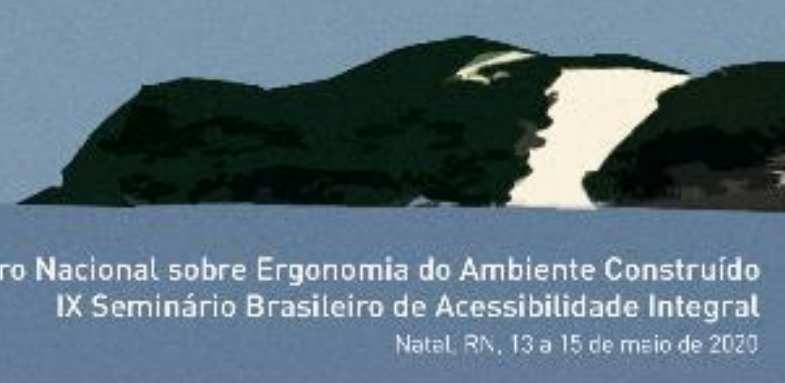

\title{
A percepção do espaço urbano por meio de estímulos sensoriais: um estudo com pessoas cegas
}

\author{
Perception of urban space through sensory stimulus: \\ a study with blind people
}

\author{
GIORDANA CHAVES CALADO TIMENI \\ Doutora, Universidade Federal do Rio Grande do Norte - Programa de Pós- \\ Graduação em Arquitetura e Urbanismo \\ (PPGAU/UFRN), Natal-RN, Brasil. giordanacaladoarq@gmail.com
}

GLEICE AZAMBUJA ELALI

Doutora, Universidade Federal do Rio Grande do Norte PPGAU/UFRN, Natal-RN, Brasil.gleiceae@gmail.com

\section{RESUMO}

Este artigo é parte da pesquisa que subsidiou uma tese defendida no PPGAU/UFRN, focada no estudo da percepção de pessoas cegas no espaço urbano, a fim de reconhecer elementos sensoriais úteis à usabilidade de todas as pessoas. $O$ texto responde a um questionamento específico da investigação: a percepção do espaço urbano por pessoas cegas. Para tanto, foi utilizado o método do Percurso Comentado a fim de analisar: (i) como a ausência do sentido da visão cria dificuldades que afetam diretamente a captura e a compreensão das informações visuais relacionadas ao meio ambiente; (ii) as estratégias desenvolvidas pelas pessoas cegas para se locomoverem no espaço. Verifica-se que tais estratégias dependem das habilidades de cada indivíduo e do tipo de relacionamento que estabelece com o local - o que inclui características do local, dimensões, distâncias, forma, posição ou possibilidade de movimento, mas também aspectos menos tangíveis como sons, odores, sensação térmica e segurança. Conclui-se que a análise do movimento do corpo cego no espaço possibilita a definição de subsídios multissensoriais para o projeto de arquitetura e urbanismo, o que pode proporcionar, não apenas mais inclusão espacial a estes indivíduos, mas maior qualidade ambiental para todas as pessoas.

PALAVRAS-CHAVE: pessoa cega, espaço urbano, percepção, multissensorial.

\section{ABSTRACT}

This paper is part of a research that supported a thesis defended at PPGAU/UFRN, focused on the study of the perception of blind people in the urban space, in order to recognize sensory elements useful to the usability of all people. The text answers a specific question of the investigation: the perception of urban space by blind people. The method of Commented Path was used to analyze: (i) how the absence of a sense of sight creates difficulties that directly affect the capture and understanding of visual information related to the environment (ii) the strategies developed by Blind people to move around the space. It appears that such strategies depend on the individuals abilities 


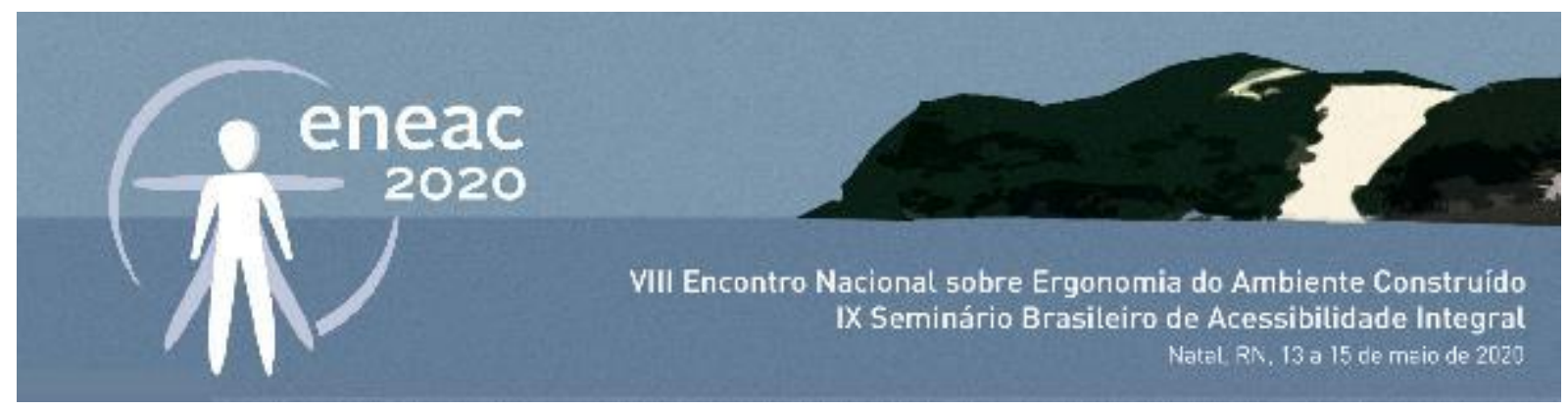

and the type of relationship that is established with the place - this includes characteristics of the place, dimensions, distances, shape, position or possibility of movement, but also less tangible aspects such as sounds, odors, thermal sensation and security. The research concludes that the analysis of the movement of the blind body in space allows the definition of multisensory subsidies for the architecture and urbanism project, not only providing more spatial inclusion to these individuals, but greater environmental quality for all people.

KEYWORDS: blind people; urban space, perception, multisensory.

\section{INTRODUÇÃO}

Qual o sentido da percepção no processo de construção do espaço? Como, ao esclarecer modos das pessoas experienciarem o ambiente em seu entorno, a percepção pode ser incorporada à atividade projetual? Indagações como estas permeiam o pensamento de muitos dos profissionais que lidam com projeto de arquitetura e urbanismo.

Academicamente o termo 'percepção' tem sido referido pelos autores a partir de compreensões diversas, tais como: sensação; recepção de um estímulo; faculdade de conhecer independentemente dos sentidos; combinação dos sentidos no reconhecimento de um objeto; representação intelectual. Tais definições trazem em si significados que dão sentido a recepção e interpretação de estímulos, a intuição, a ideia e a imagem.

Tal entendimento conduz à ideia de espaço sensível, incorporando a importância de se levar em consideração aspectos emocionais e afetivos que caracterizam a relação das pessoas com o ambiente (OKAMOTO, 2002), Aprofundando tal entendimento, Cohen e Duarte (2013, s/p), assinalam que ao interagir com o ambiente o ser humano promove "um constante dialogo capaz de produzir relações de afeto, significações e apropriações", ou seja, reafirmando Hertzberg (1991), a pessoa não apenas dá significado à sua situação no mundo, mas também reconstrói suas lógicas e aspirações, incluindo a própria concepção de mundo.

As percepções do espaço consistem não no que vemos, como também no que ouvimos, sentimos, e até mesmo no que cheiramos, assim como nas associações que despertam. Dessa maneira, a arquitetura é também capaz de mostrar o que não é realmente visível, e despertar associações de que não tínhamos consciência antes (HERTZBERG, 1991, p. 230).

Conforme Gibson (1986) uma pessoa cega ou mesmo uma pessoa vidente vendada pode sentir uma parede a sua frente, mesmo que não lhe seja possível identificar exatamente qual dos sentidos foi estimulado para fazê-lo, o que indica multissensorialidade envolvida na experiência corporal e, portanto, na percepção ambiental. Também se referindo especificamente a cegos Porto (2002), explicita que, para melhor usufruírem do potencial funcional do ambiente eles abraçam plenamente a experiência do corpo e seus recursos. Isso se explica, pois "percepção é pensamento, é reflexão que alimenta a convicção de que há qualquer coisa, de que há o mundo" (2002, p. 27), ou seja, perceber se relaciona mais à capacidade de pensar/compreender os elementos captados pelos sentidos do que aos elementos observados em si, o que permite deduzir, por exemplo, não serem os olhos os únicos "sujeitos da visão". 


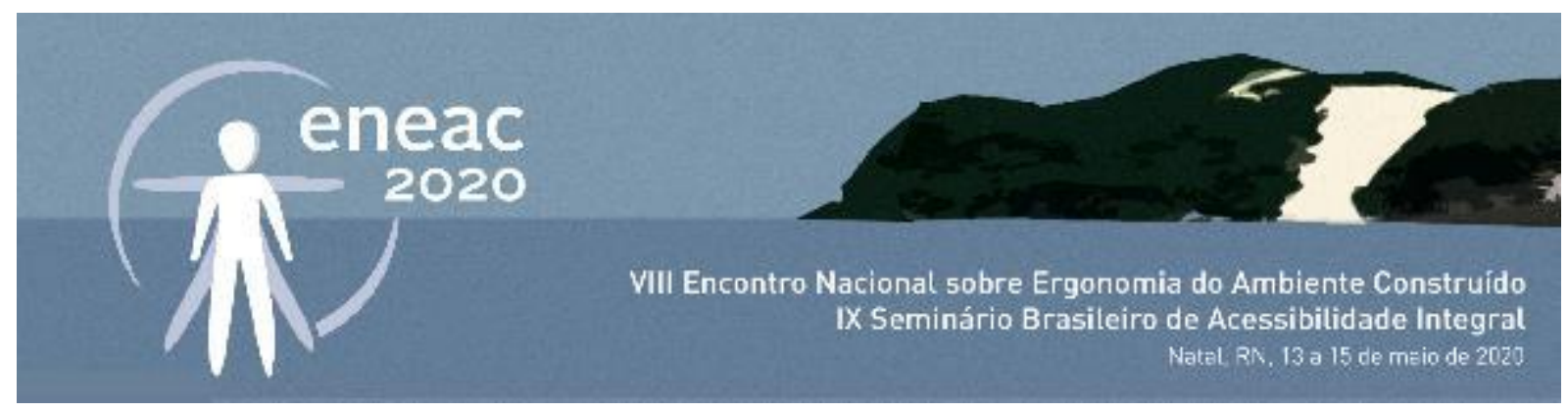

devem então ser conduzidas, depois decifradas, de modo a produzir em nós o texto original (MERLEAU PONTY, (1945/2013, P. 28)

A ênfase ao corpo coloca em evidencia a necessidade de aprofundar o conhecimento sensível, passando a melhor compreender aquilo que pode estar envolvido pelos receptores sensoriais, entendendo-se o mundo-sentido como "o mundo real interpretado pelas abstrações imediatamente fornecidas pelos órgãos dos sentidos" (LANGER, 1972, p. 85, apud TUAN, 1977/2013, p.10).

Este artigo apresenta parte de uma pesquisa sobre a percepção do ambiente por pessoas cegas usada para subsidiar a tese defendida MUITO MAIS QUE O ESCURO: a vivência espacial dos cegos como base para a compreensão sensível da cidade. Tem como objetivo apresentar como as pessoas cegas percebem e atribuem significado aos elementos existentes no espaço, para o que, além da visão, os ruídos, os odores e outros indicadores sensoriais contribuem, mesmo inconscientemente. Para tanto, o texto é composto por 03 itens: breve descrição do método, principais resultados (subdivididos em sensações sonoras, táteis-cinestésicas, olfativas e térmicas) e considerações finais.

\section{MÉTODO}

A investigação, de cunho qualitativo teve como meta a busca por informações sobre o ambiente durante o deslocamento de cegos no espaço urbano (TIMENI,2019). Para tanto buscou-se conhecer as informações sensoriais captadas no meio durante o deslocamento dos participantes cegos, tendo como base o método do Percurso Comentado (THIBAUD, 2001). O método consiste em acompanhar os participantes em uma caminhada previamente planejada, registrando a sua interação com o ambiente. Após definição do local da experiência coube ao participante a escolha do trajeto a ser percorrido. Foi necessário que eles descrevessem as sensações vivenciadas ao longo do caminho, as quais constituíram a base para a análise, conduzindo aos resultados que geraram a reflexão (dos participantes e da pesquisadora) sobre os fenômenos vivenciados.

Durante o percurso foi realizado o registro das ações como atravessar a rua, chegar ao local de destino e utilizar o mobiliário urbano, cabendo ao participante relatar, verbalmente, as impressões sobre cada local vivenciado. O diálogo foi pautado nos estímulos sensoriais identificados, fazendo emergir os elementos do ambiente urbano disponíveis a orientação, assim como o reconhecimento dos referenciais utilizados nos deslocamentos. Tal tipo de abordagem envolve, necessariamente, o entendimento desse corpo, do ambiente sensível e do movimento, com base na importância das situações vivenciadas durante o deslocamento.

O movimento do percurso realizado pelo corpo da pessoa cega foi registrado em três ângulos distintos, cujas imagens foram capturadas através de: (i) um óculos-espião; (ii) uma câmara compacta, com amplo ângulo de visão; (iii ) uma filmadora portátil - explicitados a seguir.

- O chamado 'óculos-espião' é um óculos comum de lentes escuras que, no espaço entre os olhos, dispõe de um mecanismo discreto destinado a filmar 'secretamente' o que é visualizado pela pessoa que o uso. Na pesquisa, o dispositivo era posicionado normalmente sobre os olhos do participante a fim de identificar o movimento da sua cabeça, o que concorreu para contatar a correspondência entre as informações do ambiente e o estimulo utilizado.

- A câmara compacta foi disposta em um suporte vertical posicionado um pouco acima da 


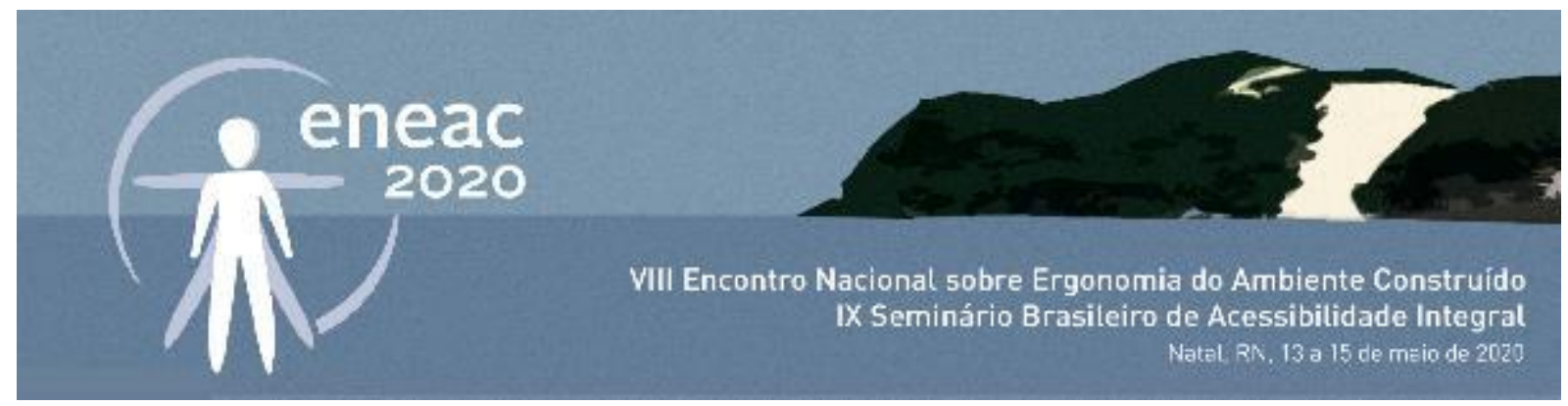

cabeça do participante, e era conduzida por uma auxiliar da pesquisa. As informações coletadas possibilitaram o registro de um amplo campo de visão da exploração espacial dos participantes, delimitado a partir dos referenciais não-visuais que utilizam, bem como da sua familiaridade com os aqueles trajetos.

- A filmadora registrou ao longe o contexto da experiência, mostrando como o deslocamento da pessoa cega é partilhado com outras pessoas ali presentes (habitantes da cidade), contexto que reflete as práticas de interação vivenciadas, os comportamentos e os hábitos inerentes a essa convivência.

Assim, ao assumir caráter subjetivo, a investigação se voltou para os significados, as motivações e aspirações dos cegos, ou seja, para o modo como tais pessoas interpretam e dão sentido às suas experiências e ao mundo em que vivem.

\section{a) Participantes da pesquisa}

A pesquisa deu enfoque a pessoa acometida por cegueira, congênita ou adquirida, com habilidade para locomoção autônoma e facilidade de verbalização, a fim de que pudessem expor suas opiniões e explicar a sua conduta diante da do trajeto. Conforme definido por Amiralian (1997), as primeiras não possuem referências visuais, enquanto as segundas compreendem o espaço a partir de antigas vivências. A investigação contemplou 5 pessoas com cegueira adquirida e 6 com cegueira congênita, subdivididos em dois novos grupos: os informantes que conheciam e que não conheciam o local da pesquisa (Quadro 1).

Quadro 1: Perfil dos participantes da pesquisa

\begin{tabular}{|c|l|l|c|l|}
\hline Participante & Sexo & $\begin{array}{c}\text { Condição da } \\
\text { cegueira }\end{array}$ & Idade & \multicolumn{1}{|c|}{$\begin{array}{c}\text { Relação com lugar } \\
\text { Experienciado }\end{array}$} \\
\hline 1 & Masculino & Congênita & 63 & Frequenta o local \\
\hline 2 & Masculino & Congênita & 44 & $\begin{array}{l}\text { Frequentou o IERC. } \\
\text { Não ia ao local ha } 1 \text { mês. }\end{array}$ \\
\hline 3 & Masculino & Congênita & 42 & $\begin{array}{l}\text { Frequentou o IERC. } \\
\text { Não ia ao local ha 8meses }\end{array}$ \\
\hline 4 & Masculino & Congênita & 23 & $\begin{array}{l}\text { Frequentou o IERC. } \\
\text { Não ia ao local ha 8 meses }\end{array}$ \\
\hline 5 & Masculino & Adquirida & 43 & Frequenta o local \\
\hline 6 & Masculino & Adquirida & 29 & Frequenta o local \\
\hline 7 & Masculino & Adquirida & 56 & $\begin{array}{l}\text { Frequentou o IERC, } \\
\text { Não ia ao local ha 6 meses }\end{array}$ \\
\hline 8 & Masculino & Congênita & 26 & Nunca frequentou o local \\
\hline 9 & Masculino & Congênita & 25 & Nunca frequentou o local \\
\hline 10 & Masculino & Adquirida & 69 & Frequenta o local. \\
\hline 11 & Feminino & Adquirida & 49 & $\begin{array}{l}\text { Frequentou o IERC. } \\
\text { Não ia ao local há 18 anos. }\end{array}$ \\
\hline
\end{tabular}

Fonte: A pesquisa 


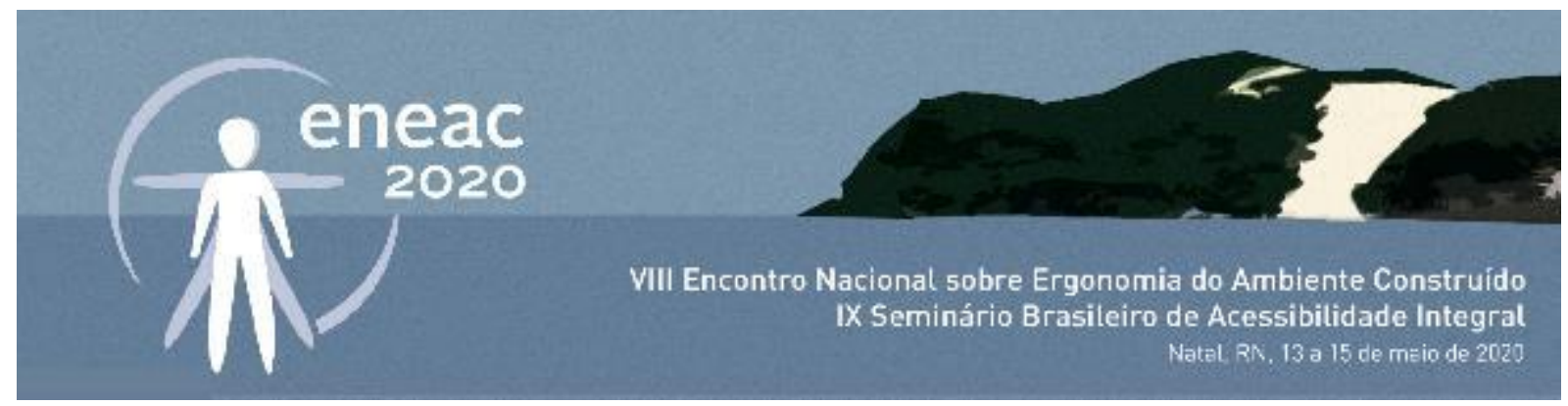

\section{b) Recorte espacial}

O cenário escolhido como palco das experiências engloba um trecho urbano (ruas e/ou avenidas) no entorno do Instituto de Educação e Reabilitação dos Cegos do Rio Grande do Norte (IERC-RN), localizado no bairro do Alecrim, Natal, RN.

O IERC localiza-se na Avenida Fonseca e Silva, uma importante via coletora da área. Trata-se de uma instituição sem fins lucrativos, de utilidade pública, que visa promover a inserção social e a melhoria na qualidade de vida das pessoas com deficiência visual, proporcionando-lhes educação, habilitação e reabilitação. Dentre outras ações a instituição disponibiliza treinamento de Orientação e Mobilidade. Servindo como referencial em seu campo de atuação, exerce forte atração sobre o público-alvo, cuja presença e circulação na região torna-se evidente.

Figura 1: Localização em Natal-RN e limites atuais do bairro do Alecrim

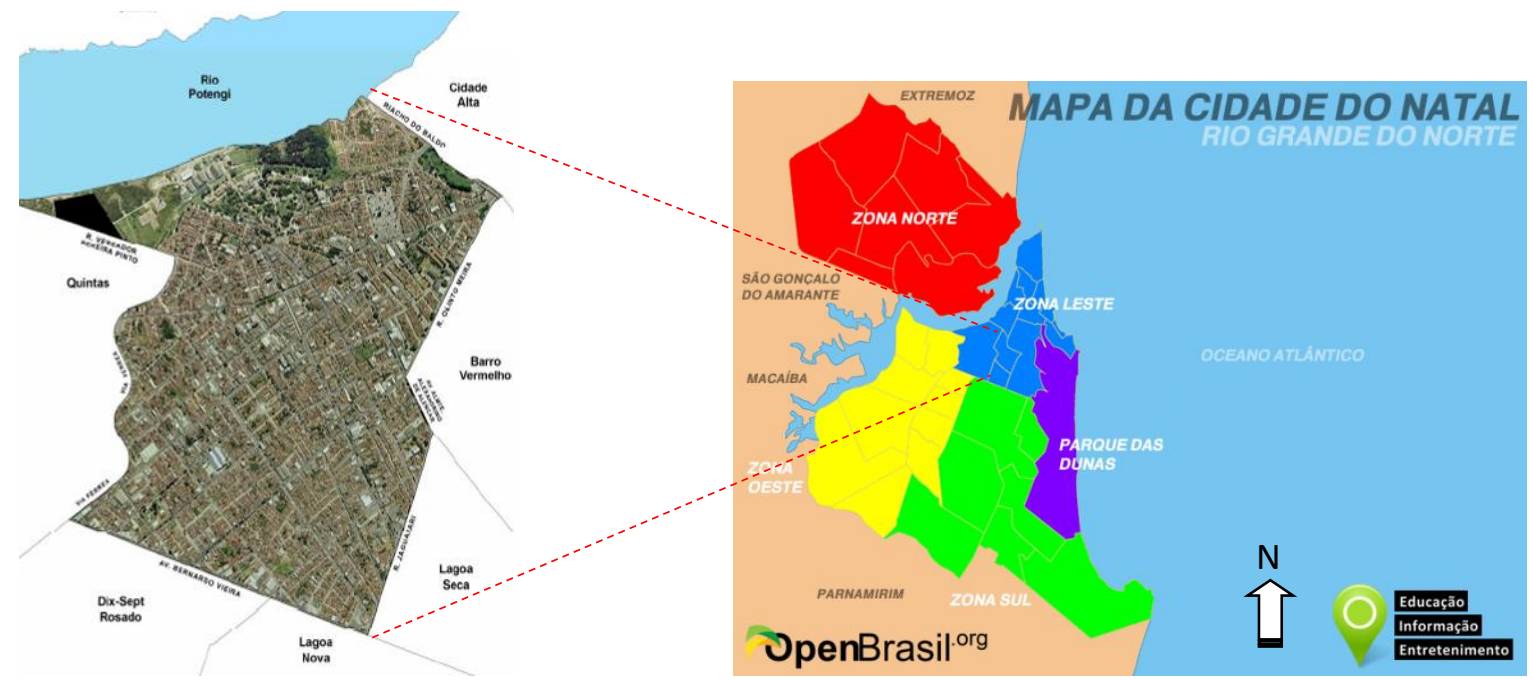

Fonte: http://www.OpenBrasil..org, e Prefeitura Municipal de Natal, Secretaria Municipal de Meio Ambiente e Urbanismo (2008)

Os caminhos percorridos foram definidos de acordo com cada participante, respeitando-se as escolhas individuais que permitissem se sentir mais confortável. Em comum os percursos deveriam ter o IERC como ponto de partida e de chegada. Para os informantes que não frequentavam o IERC, foram estabelecidos dois pontos estratégicos a atingir: o semáforo sonoro localizado na Av. Coronel Estevão e a Igreja São Pedro, em frente à Praça Pedro II. Para os participantes que frequentaram o Instituto eram solicitados dois pontos adicionais, a sua escolha: (i) um ponto que the era familiar, sendo estabelecido que seria a parada de ônibus que utilizava para chegar ao instituto; (ii) um local com o qual não era familiarizado, embora soubesse que estava nas redondezas.

\section{PRINCIPAIS RESULTADOS: ACOMPANHANDO AS PESSOAS CEGAS NA CIDADE}

O meio urbano possui características que facilmente podem ser reconhecidas pelas pessoas que dispõem do sentido da visão, tanto em seus pontos positivos quanto negativos. No entanto, quando 


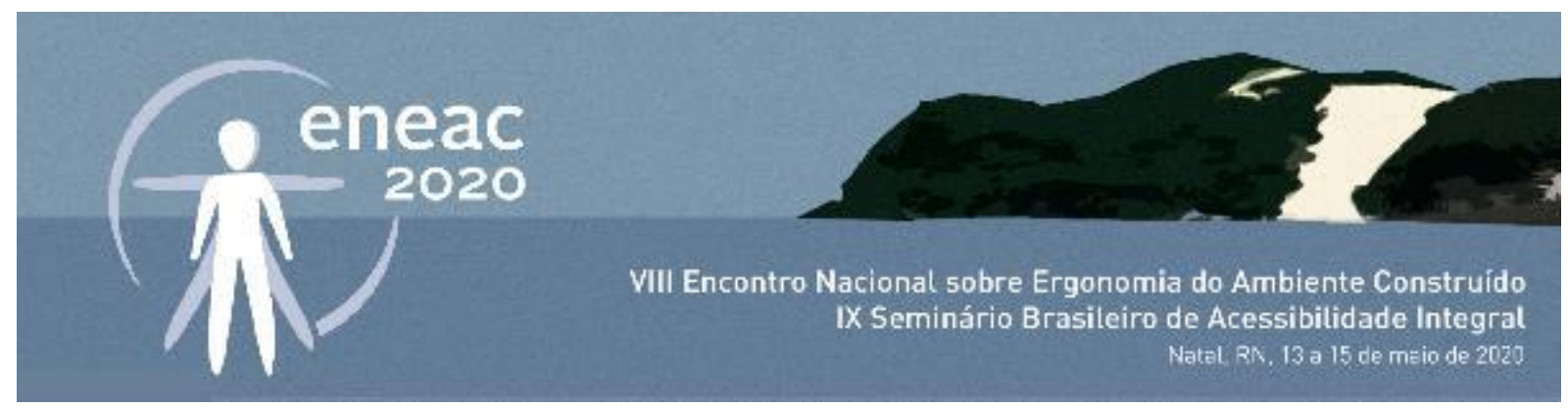

se trata da usabilidade pelas pessoas cegas (PCs) surgem dificuldades naturais para realizar tarefas dos mais diversos tipos, desde prever distâncias até localizar obstáculos, definir percursos e localizar elementos na malha urbana. Tais circunstâncias colocam as PCs diante de situações que exigem grande atenção para os estímulos sensoriais disponíveis no espaço (sinais/pistas auditivos, táteis, olfativos, etc.), além de precisarem recorrer continuamente à memória para resgatar a disposição de elementos de seu interesse (lojas, instituições, cruzamentos, passagens de pedestres e similares).

Diferentemente da percepção das pessoas videntes, para as quais ao avistar um local as demais informações acerca dele são apreendidas/ assimiladas de forma quase simultânea ou mesmo são consideradas de maior ou menor importância, a identificação do espaço pela pessoa cega ocorre de maneira mais lenta, porém contínua.

Reforçando esse entendimento e auxiliados por uma bengala, nossos participantes recorriam com frequência aos indicadores sensoriais de cada local, a fim de saberem onde estavam e de identificarem as informações do meio. Assim, muitas vezes correntes de ar sinalizam a porta de entrada de algum estabelecimento; a presença de um terreno baldio ou a chegada a uma passagem, o cheiro de alimentos denunciava a presença de uma lanchonete, os sons que caracterizam a movimentação de veículos comprovavam a sua existência e até a sua tipologia, assim como o burburinho comum à conversa dos jovens indicava a proximidade de um prédio escolar.

As informações sensoriais, portanto, são a base para a construção do conhecimento no tocante ao uso e concepção do ambiente, mas precisam ser complementadas pelas informações muiltisensoriais que, na medida em que estejam disponíveis, proporcionam caráter aos objetos e lugares, tornando mais fácil o processo de identificação e de lembrança, permitindo que as pessoas usufruam do espaço com mais qualidade e sentimento.

Para complementar é preciso entender que, estando permanentemente presentes no espaço, embora variem em algumas situações, eventualmente, algumas informações podem não ser decodificadas em conformidade com a situação real, uma vez que o próprio observador/percebedor é quem constrói ou deduz a percepção a partir de seus referenciais e necessidades. Um exemplo dessa construção mental diferenciada aconteceu com P8M26Cg, ao passar pela padaria. Enquanto a maioria dos participantes reconhecia o local a partir do cheiro de pão, o participante, além da sensação olfativa fez associações aos estímulos auditivos estimulados pelo som característico da televisão e, assim, atribuiu que o local se tratava de um restaurante. Como diz Gibson (1986), é a mente que sintetiza o significado.

\subsection{SENSAÇÕES SONORAS}

A informação auditiva é fundamental para a localização espacial, pois os sons levam ao sistema receptor muitas informações sobre o entorno imediato. Diferente da pele, que não discrimina a distância, a audição é capacitada para perceber a distância e o contexto ambiental. Nesse campo, rapidamente alguns participantes avaliaram a aproximação de carros devido a repercussão do barulho produzido pelo seu movimento:

Estamos chegando na esquina, porque o carro está passando na minha frente $E$ há mais outros vindo, uns três, todos do lado direito (P2).

Os sons comunicam grandezas como distância da fonte emissora e tamanho. Assim, uma das principais ações utilizadas pelos participantes para o reconhecimento espacial consiste em distinguir 


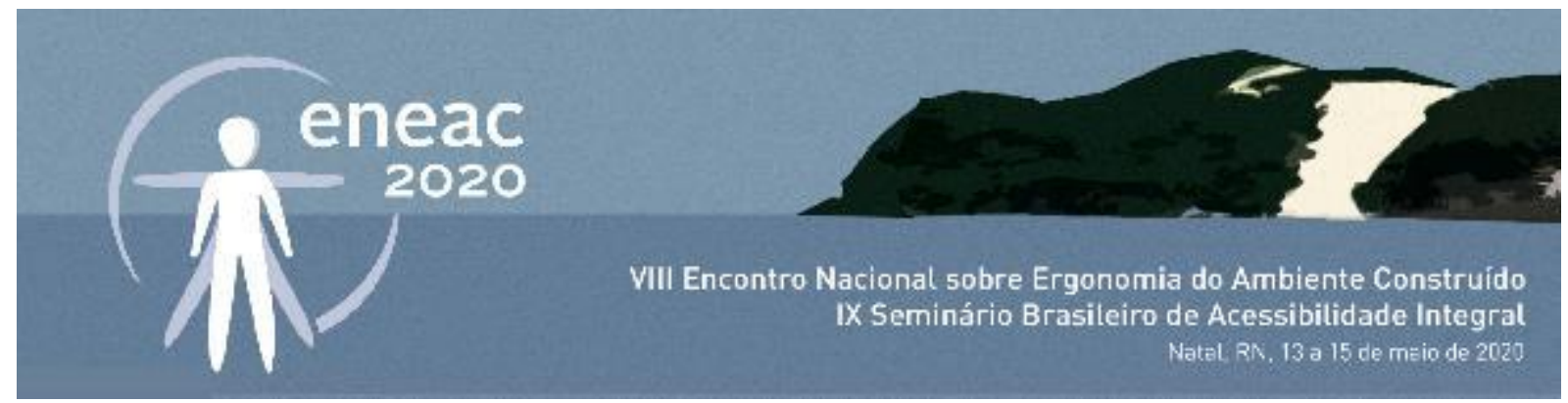

e localizar fontes sonoras, para, em seguida, comprová-las por meio de outros sentidos (como o uso da bengala ou da mão), o que lhes possibilita identificar o caráter do espaço a partir da percepção do som. Assim, P8 comentou que a direção das fontes sonoras interfere na sua localização espacial, notadamente, quando se trata de tomar decisões e de definir o destino a ser tomado. Em sentido semelhante, outro participante chamou a atenção para a percepção dos elementos do percurso:

Existe a questão da sombra sonora, que quando eu passei aqui (deixe eu voltar aqui) ficou meio que o ar, quando eu falei aqui minha voz meio que projetou, foi assim e voltou ai eu percebi que tem uma diferençazinha e quando eu ando ligeiro eu não percebo muito, mas se eu andando devagarzinho, como agora, eu percebo mais (P4).

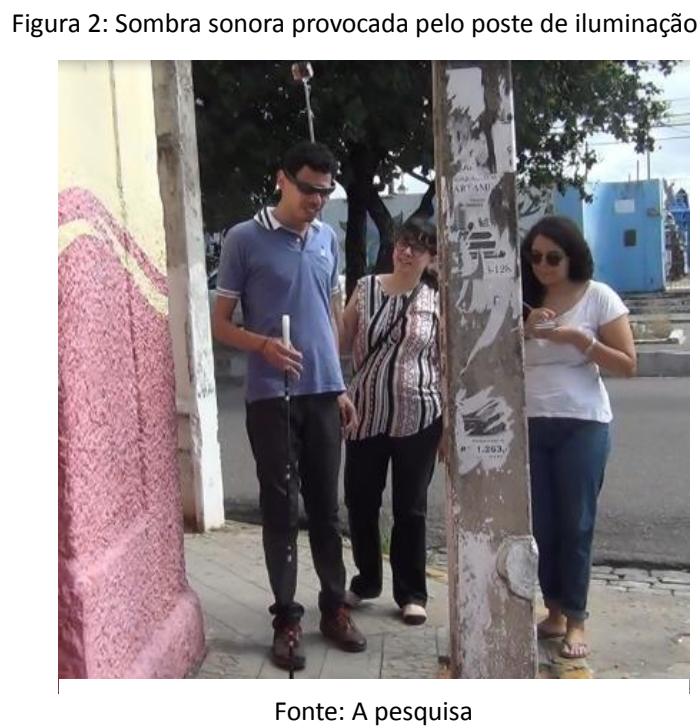

Corroborando, Tuan (1977/2013, p. 18) explica que, ao incluir áreas que estão fora do nosso campo visual, o som amplia nossa consciência, alguns participantes demonstraram distinguir as informações ambientais a partir da experimentação de mecanismos originários do toque da bengala e sua reverberação. Assim, mesmo estando em movimento eles conseguem analisar os indicadores ambientais obtidos e tomar decisões com base neles.

Conhecedor do princípio da eco-localização (localização espacial a partir de informações sonoras geradas pelo eco), P3 costuma produzir uma espécie de 'imagem mental' cuja base são os sons reverberados pelo ambiente. De acordo com esse sistema, o eco permite a pessoa identificar um obstáculo ou um ambiente por intermédio do retorno sonoro. Dentre os participantes, alguns emitem sons estalando os dedos ou a língua a fim de observar o eco gerado, recurso por meio do qual conseguem mensurar a proximidade de objetos (como aconteceu no exemplo mencionado). Nesses casos, o tempo entre o som e o eco contribui para que o participante se desloque com segurança e autonomia.

O eco emitido pelos passos ou pela bengala tocando ao solo também é utilizado em locais onde não existem portas ou para compreender que uma porta está fechada. Em ambientes externos tal recurso também ajuda a identificar a posição e a forma do muro, ou mesmo para compreender paredes sem aberturas (neste caso associado à não-passagem de corrente de ar). 


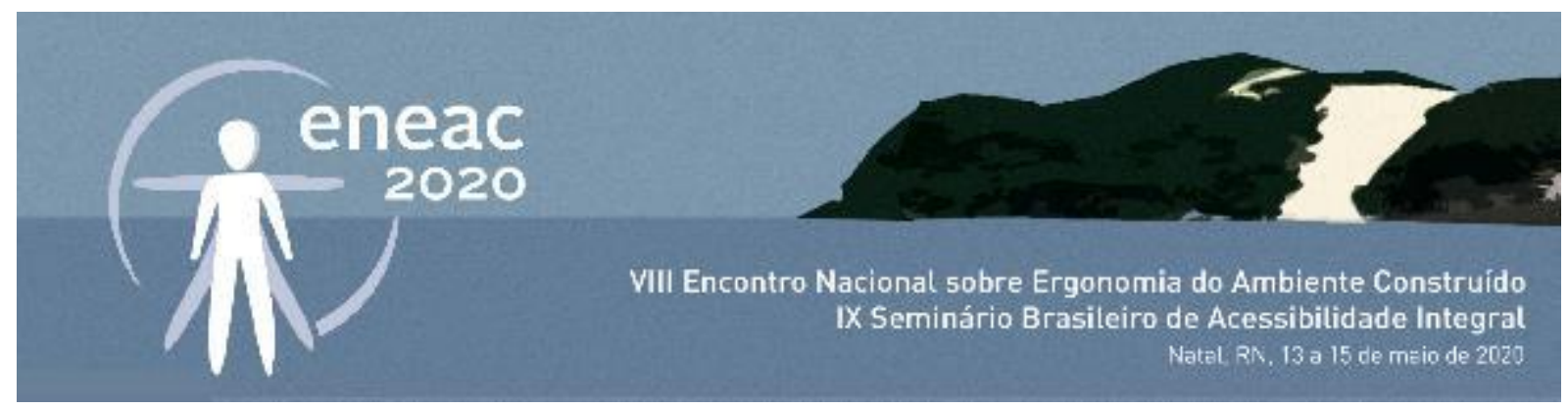

Aqui tem um obstáculo mais alto. Dá pra sentir. Eu percebo, acho que é um toldo aqui em cima, talvez. A voz do eco fica mais presa, eu consigo ter uma noção, eu olhando aqui pra cima, é como se a voz batesse e voltasse, entendeu? (P9).

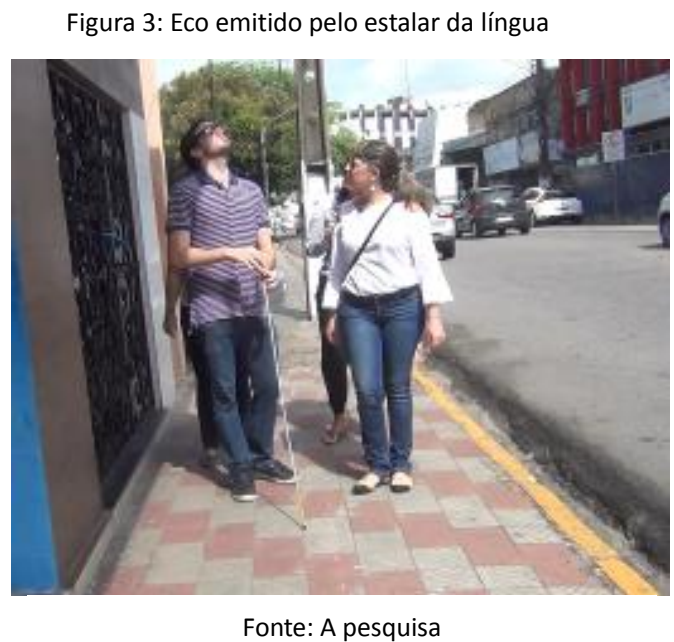

Ressalte-se, portanto, que, perceptivamente, o espaço ecoante facilita a locomoção das pessoas cegas, instruindo-as a detectar obstáculos cuja existência poderá ser comprovada/reforçada com o auxílio de outros fatores de ajuda importantes para o reconhecimento espacial, como o indicador ambiental e a guia de balizamento.

\subsection{SENSAÇÕES TÁTEIS- CINESTÉSICAS}

Os participantes cegos se mostraram sensíveis aos indicadores táteis e cenestésicos do ambiente, enfrentando diferentemente o fato de não poderem apreender de uma única vez a variedade de detalhes presentes (alcance melhor permitido pela visão).

Nesse sentido, a bengala assumiu o papel de extensão do braço em auxilio a mobilidade, dando a entender que, como outros objetos, ao ser manipulada ela transmite a sensação não apenas de texturas, mas de propriedades geométricas, massa e volume. De fato, a bengala assume a função de proteger, orientar e detectar as informações ambientais captadas por sensações táteis.

Os pés mostram-se outra fonte de informações táteis. Ao experimentar as calçadas por onde passavam, os participantes, usavam a sensibilidade dos seus pés para distinguir inclinações e imperfeiçoes do solo, conseguindo apreender e julgar com segurança as condições de higiene e de limpeza das calçadas e identificar aspectos complementares (como a origem de correntes de ar e a incidência dos raios solares). Nesse sentido, ao indicar como conseguia saber em que parte de um trajeto se encontrava, P3 explicitou vários fatores que o possibilitava compreender o mundo perceptivo e que são fundamentais para a compreensão do espaço.

Por causa da inclinação da calçada, por causa da atmosfera que muda a sombra sonora... pelo vento, enfim são várias informações que você tem (P3). 


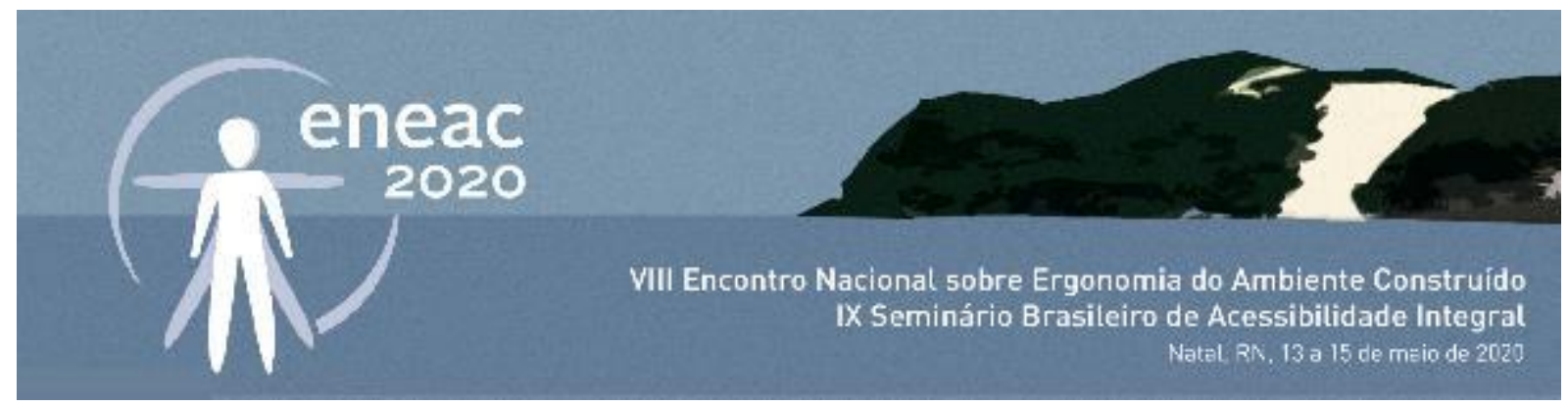

Um dos participantes refletiu sobre alguns casos nos quais a movimentação volta-se para a compreensão da própria estrutura do local em que se encontra, sendo conduzida a partir de uma indagação como: "quais são as características desse ambiente?" (P7). Na concepção do participante, para responder a esse tipo de pergunta é preciso que a pessoa explore o ambiente e, daí em diante, exercite sua memória e resgate ideias relacionadas a cada parte do ambiente.

Com relação às condições de movimentação no Bairro Alecrim, o participante relatou:

Ali pra você se deslocar é uma dificuldade grande. Problema dos ambulantes e as calçadas das lojas já não são uma coisa padronizada porque o bairro é antigo, a arquitetura é antiga, não tem essa preocupação na época. Acho que nunca teve a preocupação com a necessidade, com a visão, com a acessibilidade de modo geral. Então tem calçadas no Alecrim não tem como uma pessoa passar pela outra (P7).

Figura 4: Participante colide com mercadorias do ambulante

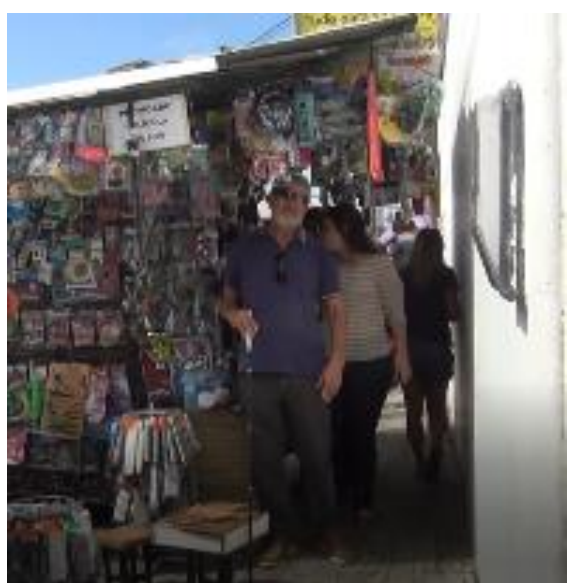

Fonte: A pesquisa

Aliás, ao dizer que se tiver algo a resolver ali, mas que possa ser solucionado em outro local optará pela segunda opção, o participante deixou claro que evita o bairro em seu cotidiano, pois percebe a precariedade das condições de mobilidade no local.

\subsection{SENSAÇÕES OLFATIVAS}

Dentre os canais sensoriais, o olfato é o receptor que, de forma mais rápida, (re)constrói memórias relacionadas a lugares, a momentos e a outras pessoas, trazendo a lembrança fatos marcantes do passado. Assim, o espaço pode ser compreendido a partir das características atribuídas pela pessoa, provindas das sensações percebidas, as quais tornam-se responsáveis pelo conhecimento, construção e do meio. Portanto, durante a caminhada pela cidade os odores característicos de cada local forneceram indícios que serviram para identificar as diferenças entre pontos comerciais (como farmácias, padarias, postos de combustível, loja de sapatos), bem como para o reconhecimento de áreas residenciais. A diferenciação que caracteriza e específica cada edificação em consequência da combinação entre estímulos e sensações produzidas foi espontaneamente demonstrada pelos participantes da pesquisa em várias ocasiões. Ao passar diante de uma residência, um deles revelou que identificara o imóvel devido o cheiro de comida caseira (P4). Outro informou que reconhecia os 


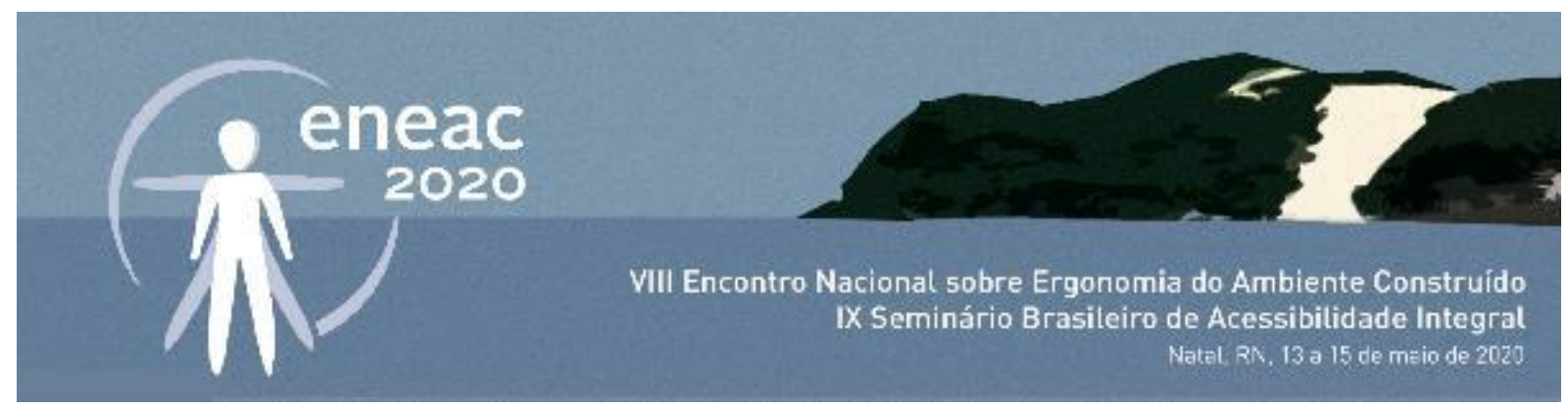

quiosques que vendiam cigarros, revistas e similares e os distinguia entre si pois "as cigarreiras vão criando cheiros e barulhos particulares" (P9).

Em sentido oposto, uma experiência surpreendente foi proporcionada a P11. Ao entrar em uma loja de confecções, o participante afirmou tratar-se de uma lanchonete. Sem entender, insistimos com a pergunta inicial: "Em que tipo de local estamos?" Ouvindo a conversa, um dos vendedores da loja revelou que acabara de passar um café e de servi-lo na loja. $O$ odor do café (que já estava bem suave e os videntes mal sentiam) havia chamado a atenção do participante, confundindo-o na compreensão imediata do local. De fato,

[...] a informação se transforma em conhecimento quando o seu conteúdo é assimilado pelo indivíduo, sendo incorporado ao rol de experiências que fazem parte de sua memória e é utilizado para a busca de solução de problemas, criação de ideias e tomada de decisões (MORAES, BELLUZZO 2004 apud MIGLIOLI, 2014).

Contudo, cabe reafirmar que, na maioria das situações, a apreensão das informações sensoriais captadas no meio acontece de forma tão integrada, que elas se complementam a ponto de ser difícil distinguir de qual dos sentidos provém determinada informação.

As informações sensoriais combinadas com o conhecimento prévio (experiência) dão sentido as conclusões (julgamento), ou, melhor dizendo, a correspondência entre os sentidos e a imaginação durante a percepção do meio ambiente se constrói sob a égide da experiência, fazendo-se necessária a atuação simultânea em todo o processo perceptivo.

\subsection{SENSAÇÕES TÉRMICAS}

Apesar do sentido térmico geralmente ser pouco mencionado nas abordagens literárias relativas aos sentidos sensoriais (OKAMOTO, 2002, p. 136), a grande sensibilidade das pessoas cegas no tocante às sensações derivadas do ambiente também fica evidente sob essas perspectiva, como foi verificado em várias oportunidades durante a vivência urbana realizada.

Caminhando pela Avenida Alexandrino de Alencar, ao nos aproximarmos de algumas árvores, embora a equipe não indicasse mudança na situação, sobretudo com relação a alteração na temperatura, P6M29Cd de imediato chamou a atenção para a diferença de 'atmosfera' que notava naquele local e a associou naturalmente à arborização, ao dizer: "A sombra é ótima aqui! Se eu pudesse armava uma rede aqui". Por sua vez, P2, explicou-nos que geralmente "o poste é a referência, mas você viu que eu não toquei no poste, eu senti a sombra dele, o sol não tá aqui, quando eu passei pelo poste o sol sumiu". E, ainda, P4 reclamou constantemente do calor vivenciado no percurso, a ponto de pedir para interromper o trajeto a fim de comprar água. 


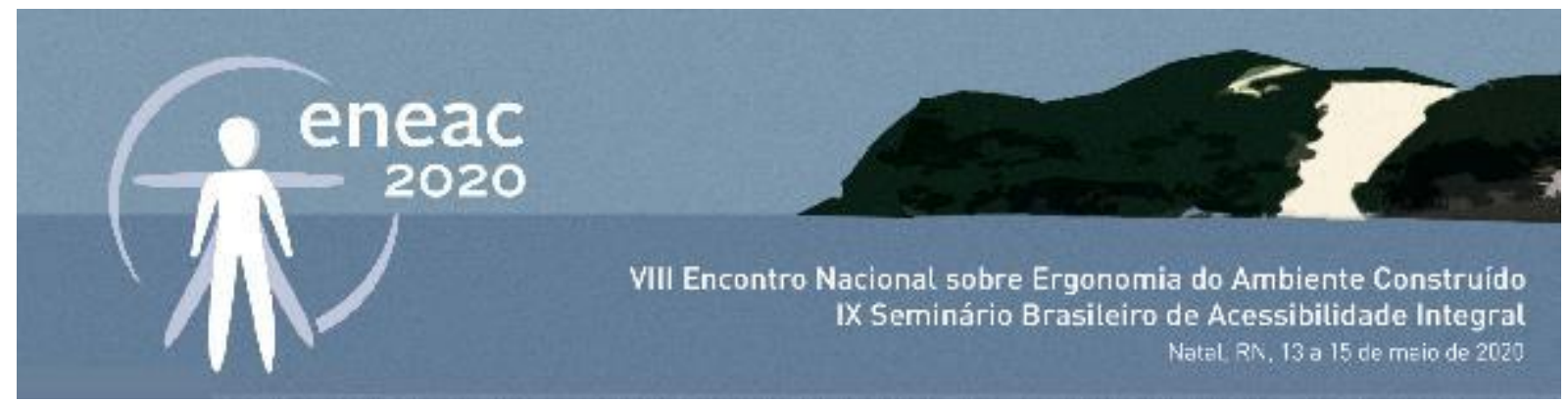

Figura 5: Conforto proporcionado pela arborização

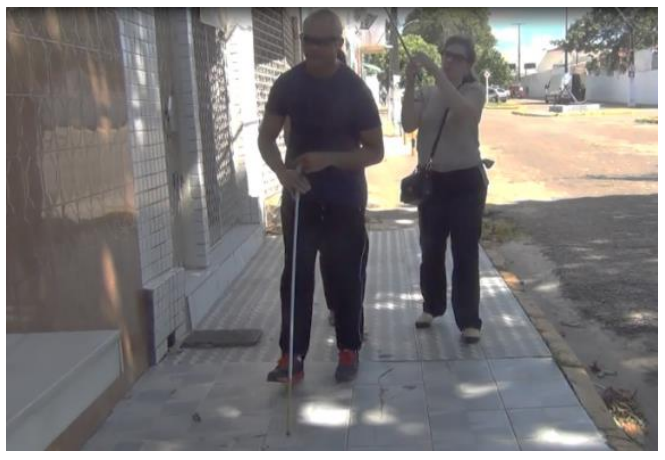

Fonte: A pesquisa

De fato, a sensação térmica é a forma dos nossos sentidos perceberem a temperatura atmosférica que, por sua vez, depende de condicionantes como umidade, densidade e velocidade do vento, as quais afetam as transferências de calor entre o corpo e o ar. Como a pele é o maior órgão do corpo humano, inclusive com capacidade perceptiva e sensibilidade diferenciada em cada área do corpo, é através dela que nos conectamos com a atmosfera e a temperatura do espaço (sensações de frio e calor), e identificamos locais mais e menos agradáveis: Assim, quando o sol incide diretamente sobre a pele de uma pessoa, Ihe é transmitida uma sensação de ardor, que reduz com a diminuição da intensidade dos raios (no fim da tarde ou numa sombra). Também o vento quente ao bater na pele, dependendo da sua velocidade ou umidade do ar poderá parecer frio enquanto em movimento, mas ao parar deixa-nos perceber com maior realismo a sua temperatura mais elevada.

Hall (1966/2012) ressalta que os cegos são fonte de dados sobre a sensibilidade à radiação, embora geralmente eles falem pouco sobre o tema

A pele é uma fonte muito mais constante de informações a certa distância do que eu jamais tinha suposto. (...) Entretanto, [os cegos] não têm consciência de sua própria sensibilidade ao calor no sentido técnico e [geralmente] não falam sobre o assunto (HALL, 1966/2012, p. 72-73).

\section{CONSIDERAÇÕES FINAIS}

No decorrer da pesquisa ficou claro que cada participante desenvolve um modo particular de lidar com as situações que se apresentam, recorrendo a estratégias próprias para facilitar a exploração do espaço, que não está condicionada apenas ao uso das mãos ou dos pés, e sim deriva da experiência do corpo inteiro. Tal variedade justifica-se porque as pessoas são diferentes e possuem formas específicas de experienciar o espaço.

Com isso, reconhecemos que o contato sensível e interpessoal no ambiente, apesar de sua natureza subjetiva concorre para a identificação e o reconhecimento de seus significados. Como diz Ponty : "Embora a percepção tenha natureza subjetiva e varie de pessoa para pessoa, entende-se que esse contato sensível e interpessoal no ambiente favorece o (re)conhecimento de seus significados" (MERLEAU-PONTY, 1945/2011).

De fato, diferentes modos de percepção no meio urbano manifestam-se nos fatos e 


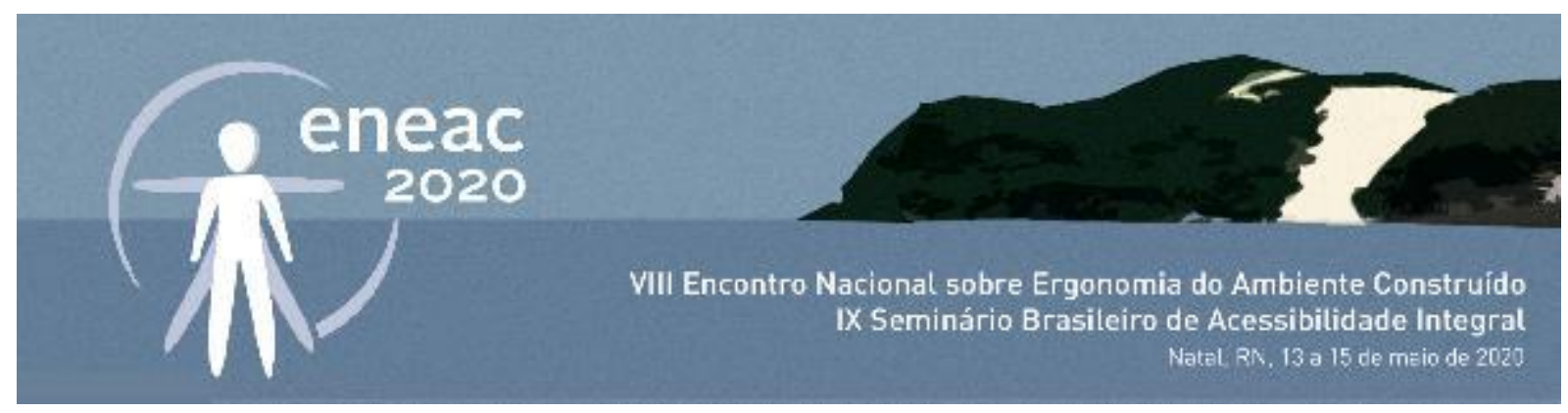

gestos dos transeuntes; inscrevem-se nas situações mais banais, e cristalizam-se na estrutura construída das cidades (THIBAUD, 2010, s/p).

A apreensão do conhecimento espacial é facilitada a partir da experiência, adquirida por meio dos estímulos vivenciados no meio ambiente, e assim, na mesma proporção em que era constatada uma maior frequência por parte dos participantes no espaço urbano, aumentava a sua capacidade de domínio, de apropriação espacial, fato este que nos permite afirmar que, a mobilização sensorial e a experiência contribuem para que a pessoa cega adquira confiança no espaço.

\section{AGRADECIMENTOS}

Aos participantes da pesquisa, colaboradores anônimos deste estudo; ao IERC e ao PPGAU/UFRN, pelo apoio à investigação; à CAPES, pela bolsa de produtividade da segunda autora.

\section{REFERÊNCIAS}

AMIRALIAN, M. L. T. M. Compreendendo o cego: Uma visão psicanalítica da cegueira por meio de desenhos-estórias. São Paulo: Casa do Psicólogo, 1997.

COHEN, R.; DUARTE, C. R.; BRASILEIRO, A. Acessibilidade plena a Museus: Perspectivas de uma acessibilidade cultural, sensorial e emocional. In: ENCONTRO NACIONAL DE ERGONOMIA DO AMBIENTE CONSTRUÍDO (ENEAC 2013). Anais do ENEAC2013, Florianópolis: ENEAC, s/p.

FROYEN, H. Designing The Dark: An Experimental Design Workshop. In: DEVLIEGER, P.; RENDERS, F.; FROYEN, H.; WILDIERS, K. Blindness and the Multi-Sensorial City. London and Philadelphia: Garant, 2006, pp. 329-338.

GIBSON, J. J. The ecological approach to visual perception. Hildale, New Jersey: Lawrence Eribaum, 1986.

HERTZBERG, H. Lições de Arquitetura. São Paulo: Martins Fontes. 1991.

LANDRY, C. A Paisagem Sensorial das Cidades. Lisboa: Building Ideas, 2017.

MERLEAU PONTY, M. Fenomenologia da Percepção. São Paulo: Martins Fontes, 2011 (originalmente publicado em 1945).

OKAMOTO, J. Percepção Ambiental e Comportamento: visão holística da percepção ambiental na arquitetura e na comunicação. São Paulo: Editora Mackenzie, 2002.

THIBAUD, J.P. La méthode des parcours commentés. In: M.GROSJEAN; J. P. THIBAUD (Org.). L'Espace Urbain em Méthodes. Marseille: Éditions Parenthèses, 2001, pp 29-45

TIMENI, G. C. C. MUITO MAIS QUE O ESCURO: a vivência espacial dos cegos como base para a compreensão sensível da cidade. Tese (Doutorado). Programa de Pós-graduação em Arquitetura e Urbanismo (PPGAU). Universidade Federal do Rio Grande do Norte (UFRN), 2019, 285p.

TUAN, Yi-Fu. Espaço e Lugar: a perspectiva da experiência. Londrina: EDUEL, 2013. 